\title{
Mountain running
}

Of course it wasn't going to be like any other race-certainly not a road race, or even a cross country. It may be quite a small mountain at 2262 feet, but it rises from its grassy foothills into an impressive rocky point. We knew Cnicht well from many a happy family day's climb: with rucksacks, dog, and children (of various sizes and speed) we would amble up, enjoy our picnic and the view, to return in the afternoon.

I was drawn back again to the home made poster in the fish and chip shop window. Last year's winner's time really was only a bit over half an hour - and that was up and down. I felt that familiar runner's challenge. What would my time be? Although only a very average runner, I knew I'd been hooked.

The day was characteristically North Welsh. All the mountains were lost in cloud as we gathered in the little village school yard. I sized up the field. Vests revealed local namesHebog, Eryri-but also clubs from afar, such as Keswick, Ambleside, and Pennine Fell Runners. Some people had come a long way. All ages-possibly even a wider spread than your average half marathon. At the very least, they were an experienced lot.

A quick warm up-just 200 yards up the lane was enough to raise the heart rate ominouslythen we gathered at the bottom of the hill. The evocative smell of embrocation and not very funny jokes made the start familiar anyway. We were off.

About 100 of us pounded up the deceptively steep lane, which lost its tarmac irrevocably after a few minutes. I looked around: there seemed to be a special-stride head down, forward bend-as if we were running into adverse circumstances (which of course we were). It helped to imitate it. The lane deteriorated further into a rocky path like a dried up river bed (which it was). We must have run only a mile or so, but I felt terrible. However, the head down approach proved useful: with loose stones underfoot you needed to see where your feet were going as we clattered along, pushing rocks behind us and struggling upwards.

The surface changed abruptly into a flatter, grassier area. Bewilderingly, the runners fanned out. It seemed there was no one way so I decided to hang on behind a Welsh club name. Unfortunately, this more agreeable cross country section quickly gave way to a rock scramble. The relief at finding running was now impossible was lost with the realisation that climbing felt even more exhausting.

And all the time visibility was worsening. I stuck as close as I could to the Welsh vest in front. An occasional marshall would loom up out of the mist with encouraging words.
Ever on, up and up. It was by now a hands and feet job: the top must be near. Suddenly a shower of small stones and a runner flew over me. The leaders were on the way down! Others followed depressingly quickly as I stumbled onwards. A marshall was shouting. I staggered on, and then realised it was at me: it was the top.

With a wave of relief I spun round and careered downhill. The relief was short lived. Descending was of course as taxing as climbing. A figure ran past me with great flying strides, as if dancing effortlessly, arms outstretched. As before, I tried the noble art of imitation but conscious of my ankles and their importance I began to appreciate the special skill of fell running. At least I had my knobbly cross country shoes on. With an extra effort I caught up a dancer and followed in his foot steps as best I could: it was exhilarating.

At last, a few spectators heralded the re-emergence of the path. High on endorphins, confused by the speed of the descent and disorientated by the mists I had no idea how far we had to go. One bit of rock scramble seemed to be pretty much like another. But the switchback lane returned and there at the bottom was the school, families, and relief. That last sweet surge-in this respect at least similar to every other race-and I was gulping the cold water.

Munching a welcome sandwich, I watched the rest coming in. I'd taken about 45 minutes and was half way down-or was it up?-the field. I found it hard to believe that I'd actually run up and down the mountain in such a short time. The winner was a local in 33 minutes and they went on coming in well past the hour. The last never appeared. Sally from Wrexham got lost, but happily wandered down much later.

Prizes were given out in the playground. The organiser thought he'd take a photo of the winners, but found he'd forgotten his camera. Thus the race ended on a characteristically informal note. Several runners washed in the river. Others just got on their bikes and disappeared, hill men as they were, into the hills.

It was certainly different. We shared a greater sense of achievement than in a normal race, with a warmer feeling of companionship than in a road race or even a cross country. I had realised that there were new running skills to be discovered, and learnt. I've talked as much about Ras Y Cnicht as the London marathon, the previous high point of my running life. In a way, that small mountain-modest, I know by mountain running standards-has become my new peak.

And with typical runner's perversity, I now look forward to more mountains! 